\title{
Birds of Chile: A Photo Guide
}

\section{Contents}

How to Use This Book. . . . . . . . . . . . . . . . 8

Area and Species Covered..................... 8

Format............................

Abbreviations and Some Terms Explained .............. 9

Introduction. . . . . . . . . . . . . . . . . . . 11

Geography, Habitat, and Bird Distribution ............ 11

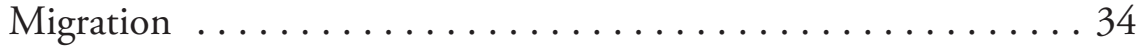

Taxonomy and English Names.................... 35

Species Accounts and Plates . . . . . . . . . . . . . . . . . . . . 37

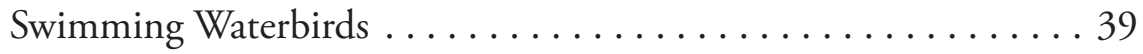

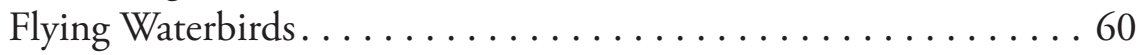

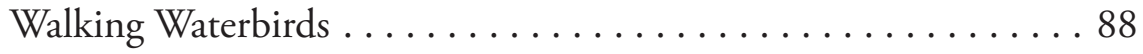

Gamebirds and Allies . . . . . . . . . . . . . . . . . 123

Raptors and Owls............................. . 129

Larger Landbirds ............................. 144

Aerial Landbirds............................. 155

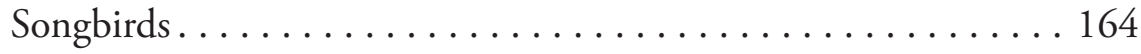

Appendix: Rare and Local Species . . . . . . . . . . . . . . 230

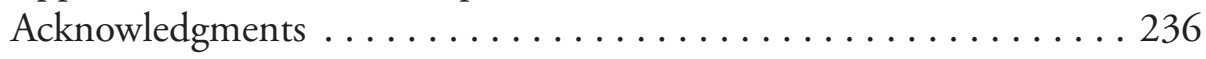

References ................................237

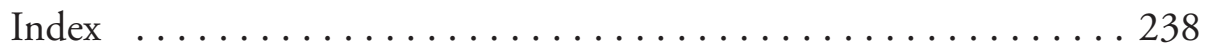

